\title{
Voluntad de vivir o voluntad de poder: Un episodio del debate de Nietzsche con Schopenhauer (1885-1889)
}

\author{
SANDRO BARBERA
}

En el capítulo de Ecce homo titulado «Por qué soy tan inteligente» ${ }^{1}$, el lector se topa con un pasaje que la condensación estilística y conceptual hace difícil de interpretar. En él, Nietzsche opone a la máxima nosce te ipsum, que presupone un sujeto capaz de conocerse a sí mismo como si fuese claramente una substancia, una «astucia» (Klugheit), que consiste en dejar que la 'tarea' o el 'destino' se afirmen a través de toda la variedad de las acciones y de las resoluciones, incluidos «los pasos en falso de la vida, las temporáneas desviaciones y los caminos perdidos, las vacilaciones», etc., y las recoja todas bajo una forma que no excluya las instancias y los experimentos, inclusos los negativos y fallidos que han marcado el trayecto. «Llegar a ser lo que se es presupone que no se tenga la más mínima de lo que se es [was man ist]». En el prefacio de 1886 a Humano, demasiado humano ${ }^{2}$, hay un pasaje que tiene una afinidad evidente con éste de Ecce homo. Ahí también se habla de una forma que crece lentamente, de una «destinación» (Bestimmung) o de una «tarea» que dispone de nosotros como un «embarazo inconsciente», aún antes de que tengamos la más mínima noticia de ello: se trata del problema del ordenamiento sobre la base del rango, que sólo se impone como el problema esencial para los espíritus libres a través de «preparativos, vueltas y más vueltas, pruebas, tentativos y enmascaramientos».

La astucia que el pasaje de Ecce homo opone al (auto)conocimiento de un sí mismo-substancia es la misma que años antes Nietzsche había presentado como principal característica del cuerpo. En el fragmento 34[46] de abriljunio $1885^{3}$, por ejemplo, «aquella cierta unidad que hay en mí» no la hace depender del yo consciente, ni tampoco de las tradicionales facultades del «sentir, querer y pensar», sino justamente de la «astucia de mi organismo en

${ }^{1} \mathrm{EH} \S 9, \mathrm{KSA}$ VI 293.

${ }^{2}$ HH Prefacio, §7, KSA II 21-22.

${ }^{3}$ KSA XI 434. 
su conjunto», que tiene en sí mismo la capacidad de conservar, de asimilar, de separar y en fin de vigilar los múltiples procesos que lo constituyen. El término designa entonces una secreta coordinación de las partes y de los procesos orgánicos (en su mayoría de carácter inconsciente e inaccesibles para nosotros), respecto a la cual el yo consciente no es más que un 'instrumento'. En un fragmento un poco posterior ${ }^{4}$, titulado «Moral y fisiología», importante también porque desarrolla aquel tema del 'mando' que hallamos en el pasaje de Ecce homo, y que constituye el momento decisivo en la reflexión sobre la voluntad de poder ${ }^{5}$, el cuerpo es presentado como el «milagro de los milagros», porque en él se manifiesta, sin la intervención de una consciencia, la síntesis de una variedad inmensa de seres vivos, cada uno de los cuales efectúa de manera autónoma la propia voluntad y el propio mando, de modo que para la coordinación y subordinación de todas estas actividades no se debe suponer que esté obrando una obediencia ciega y mecánica, sino una obediencia «que elige, es inteligente, llena de precauciones, que se contrasta a sí misma». La sorprendente síntesis del cuerpo, su dialéctica del mandar y obedecer 'inteligentes', efectuados por ambas partes, es tan superior a la síntesis hecha posible por el espíritu y las facultades del pensar-sentir-querer, cuanto lo es el álgebra a la tabla pitagórica ${ }^{6}$.

Volveremos más adelante a este fragmento, pero lo poco que hemos visto hasta ahora sirve para establecer que la reivindicación en Ecce homo de la 'astucia' es un indicio del radical desplazamiento de perspectiva que Nietzsche efectúa respecto al léxico y a los conceptos de la teoría tradicional de las facultades del alma. Nos hallamos pues ante un texto en el que los términos de la tradición filosófica -instinto, espíritu, razón, facultad, cualidad, etc.- son sometidos a una tratamiento irónico que los desvincula del significado originario, para obtener de ellos nuevas e incluso paradójicas prestaciones semánticas. Por ejemplo, en un texto como éste: $\ll_{i} Y$ cuidado también con las grandes palabras, con las grandes actitudes! Son todos peligros de que el instinto se entienda demasiado pronto -Mientras tanto, en lo profundo, crece cada vez más la 'idea' que organiza, la idea llamada a dominar- ella empieza a mandar, lentamente guía los pasos atrás de las desviaciones, de las vías perdidas, prepara las cualidades y capacidades [Qualitäten und Tüchtigkeiten] específicas, que después se revelarán indispensables como medios para el todo -elabora sucesivamente todas las facultades [Vermögen] subordinadas, antes de hacer trasparentar algo de la tarea dominante, de la 'meta', del 'fin', del 'sentido'. Vista por este lado, mi vida es sencillamente maravillosa. Quizás, para la tarea

${ }^{4}$ KSA XI 576-579, 37[4].

${ }^{5}$ Cf. W. Müller-Lauter, «Nietzsches Lehre vom Willen zur Macht», Nietzsche-Studien, 3, 1974, p. 3.

${ }^{6}$ KSA XI 557. 
de una transvaloración de todos los valores eran necesarias facultades mayores de las que se ha hallado nunca en una misma persona, y sobre todo facultades opuestas, pero que no pudiesen ni molestarse ni destruirse. Ordenación de las facultades según su rango; distancia; el arte de dividir sin enemistar; no mezclar, no 'conciliar' nada; una enorme multiplicidad, que es el opuesto del caos- todo esto ha sido condición preliminar, el largo secreto trabajo y artificio de mi instinto. Su alto patronazgo se me ha demostrado tan fuerte que nunca he adivinado qué es lo que crecía en mí -y así todas mis capacidades se han destapado un día de improviso, maduras, en su máxima perfección. No consigo acordarme de haberme nunca esforzado- en mi vida no se visulmbran signos de lucha, yo soy el opuesto de una naturaleza heroica».

El instinto se convierte en el objeto de una operación esencialmente racional, más aún, de la más alta de todas ellas, como es el conocimiento de sí mismo; por otra parte, el motor de la organización que se desarrolla 'en las profundidades', a espaldas de la consciencia, y que se supone que es una fuerza instintiva, es una 'idea', el producto más alto de la razón.

¿Qué induce a Nietzsche a usar la palabra 'idea'? Entre los distintos modelos que podía utilizar para definir una función hegemónica y ordenadora de una pluralidad de impulsos dinámicos, que van unidos o en conflicto, podría estar la noción de faculté maîtresse con la que se topa leyendo el artículo de Taine sobre Napoleón en la Revue des deux mondes del 15 de febrero de 1887. Nietzsche anota enseguida la expresión ${ }^{7}$ y un poco más tarde la aplica también a Wagner. En el prefacio a la Historia de la literatura inglesa (Nietzsche la poseía tanto en original como en traducción), Taine había expuesto con profusión el concepto y había hecho de la faculté maîtresse o disposition maîtresse o trait commun, tanto la función dominante como el signo morfológico de una civilización, en cuanto que puede ser entendida como el elemento común de un cuerpo orgánico.

Adelanto no obstante la sospecha, que más adelante intentaré apoyar por otros indicios, que un modelo más influyente en Nietzsche fue la noción schopenhaueriana de idea, tal y como aparece, no en el tercer libro de El mundo como voluntad y representación, donde sirve de punto de apoyo para un análisis de la intuición estético-genial del mundo, sino en el segundo libro, donde sirve de base, en cambio, para una auténtica filosofía de la naturaleza. En cuanto objeto de la contemplación genial, desprendida de los impulsos de la voluntad, la idea es un representación potenciada en símbolo (en la acepción que tiene el término en Goethe), una imagen que consigue reunir en sí misma las características de la universalidad y la particularidad. En el segundo libro de El mundo, la idea es equiparada a la fuerza, y aparece en el conjunto de un

${ }^{7}$ Cf. KSA XII 223-224, 5[91], 
proyecto de filosofía de la naturaleza, donde la voluntad es utilizada como un principio de explicación dúctil, con el fin de determinar un 'plan' unitario de la naturaleza sin ahogar las diferencias entre sus reinos. En abierta polémica con el reduccionismo mecanicista y con la introducción de una fuerza vital extraña a la materia, Schopenhauer expone una jerarquía de las fuerzas (generales, mecánicas, químicas, orgánicas y morales) que son todas, a distintos niveles, manifestaciones de la voluntad y son equiparadas a las ideas, «formas eternas o modelos». Dentro de esta imagen de la naturaleza como teatro de fuerzas que expresan, según una escala jerárquica, los grados de objetivación de la voluntad, las fuerzas o formas superiores aparecen como 'potencias' (en sentido matemático) de las inferiores, y la entera vicisitud de las fuerzas es alimentada por el conflicto, que constituye su motor y su referencia común. Cada idea es tal porque ha vencido y 'se ha tragado' a las otras ideas o, según el lema citado también por el joven Nietzsche, serpens, nisi serpentem comederit, non fit draco.

Me detendré más adelante en la característica schopenhaueriana del conflicto, que parece ser lo que más atrajo a Nietzsche en sus últimos años. De todos modos, en la definición del conflicto entre las formas y los fenómenos es esencial el hecho de que revela la íntima escisión o 'disidio' (Entzweiung) de la voluntad. La voluntad misma se presenta como una estructura polar, atravesada y escindida por un conflicto que le pertenece de manera esencial, «un conflicto [Widerstreit] que lacera internamente a la voluntad ${ }^{8}$, y del que depende el antagonismo de sus manifestaciones fenoménicas. Schopenhauer no da muchas pistas al lector sobre la dependencia de la Entzweiung respecto al conflicto que reina en la multiplicidad fenoménica de la voluntad: es un tránsito que él se limita a enunciar, pero que se vuelve más claro si se piensa que en este caso se refiere, como muestra también el uso del término Poten$z e n$, al modelo de 'física especulativa' propuesto por Schelling, en el Erster Entwurf eines Systems der Naturphilosophie y en la Einleitung zum Entwurf. Además de compartir el programa general de Schelling, de «reconducir los productos orgánicos e inorgánicos a una expresión común», lejana tanto del vitalismo como del mecanicismo, Schopenhauer sigue además algunas estructuras conceptuales del escrito schellinguiano. Para Schelling, en efecto, el tránsito de la naturaleza desde el estado de 'puro sujeto' (natura naturans) al de 'objeto en sí' (natura naturata) sólo es posible si es pensada, no como identidad, sino como duplicidad (Duplicität o Entzweiung). Esto significa que «ya en la productividad originaria de la naturaleza existen fuerzas opuestas», que «su originaria duplicidad es un conflicto [Widerstreit] de tendencias realmente opuestas» ${ }^{9}$ : gracias al mecanismo de la reproducción ellas no se anulan

${ }^{8}$ A. Schopenhauer, El mundo como voluntad y representación, vol. I, libro II, §27.

${ }^{9}$ F.W.J. Schelling, Einleitung..., en Ausgewählte Schriften, ed. M. Frank, Suhrkamp, Fran kfurt a. M., 1985, p. 356. 
recíprocamente, sino que la tendencia negativa opera como 'obstáculo' para la positiva, dando lugar (como en el fenómeno de los vórtices que se crean cuando un obstáculo se opone a la corriente) a las formas individuales.

La derivación de la pluralidad respecto de la duplicidad es perfeccionada luego en El mundo por un tercer momento esencial, que reconduce a identidad tanto la pluralidad como la duplicidad, y que Schopenhauer ha expresado con la figura de la eterna justicia. Ella es el reconocimiento de la identidad de aquello que en el conocimiento fenoménico aparece como diferente o antitético, y permite por ello determinar la raíz nouménica de la lucha que se halla universalmente difundida en la naturaleza y entre las formas de objetivación de la voluntad: «Arrastrada por su ímpetu, [la voluntad] descuartiza la propia carne, sin saber que está lacerándose a sí misma, se engaña y saca así a la luz, por medio de la individuación, el conflicto interior que se esconde en su seno. Carnicero y víctima son una sola cosa, y ambos yerran, creyendo el primero estar privado del martirio, la segunda ser ajena a toda culpa» ${ }^{10}$.

Es evidente que en el fondo de la idea de justicia eterna, en la que todas las oposiciones que aparecen en el mundo fenoménico como existencias separadas, constituyendo una multiplicidad, se vuelven visibles como 'caras distintas' y sin embargo idénticas de la misma voluntad, se halla el problema no resuelto de la individuación, el cual ya había atormentado a Nietzsche en los más tempranos apuntes sobre Schopenhauer, redactados en Leipzig. En efecto, ya en el tema de la idea está presente una instancia de pluralidad: este acto de la voluntad es, al par del carácter inteligible, una individuación que no depende de las condiciones formales de la intuición, el espacio y el tiempo; representa el problema de lo Uno y lo Múltiple, y remite por ello a lo que Schopenhauer ha considerado siempre -aunque no de modo evidente en los textos destinados al público- el nudo o el 'abismo' de su filosofía, el problema de «cuán profundamente las raíces de la individualidad se remontan a las raíces de la esencia en sí del mundo» ${ }^{11}$.

En la época de El nacimiento de la tragedia, Nietzsche ya había afrontado este conjunto de pensamientos. Con la noción del 'Uno originario' había intentado sustituir la unidad metafísica de la voluntad por una estructura polar en la que el choque entre opuestos se descarga con la producción de una imagen. En el escrito contemporáneo La filosofía en la época trágica de los griegos, la conexión en Heráclito entre lucha y juego es introducida mediante un elaborado paralelismo con Schopenhauer. Citando un pasaje de El mundo, referente a la naturaleza en su conjunto, Nietzsche observa que: «el tono fundamental de estas descripciones sigue siendo distinto al de Heráclito, en tanto que para Schopenhauer la lucha es una demostración de la escisión interna a la

${ }^{10}$ A. Schopenhauer, El mundo como voluntad y representación, vol. I, lib. IV, §63.

${ }^{11}$ Ibid., vol. II, cap. L, Epifilosofía. 
voluntad de vivir, es un auto-devorarse de este impulso oscuro y obtuso, es un fenómeno siempre terrible que nunca da felicidad» ${ }^{12}$.

La comparación estrecha entre el filósofo antiguo y el moderno está presente también en las lecciones de Basilea sobre Los filósofos preplatónicos, aunque aquí no se cita en ningún momento el nombre de Schopenhauer. En este texto el concepto de díke se presenta como «el segundo concepto principal, junto al de pólemos» y la unión de ambos como «el primer pensamiento específicamente helénico de la filosofía» ${ }^{13}$. Pero sólo en La filosofía en la época trágica de los griegos, la «díke inmanente» de Heráclito recibe el nombre estrictamente schopenhaueriano de 'justicia eterna'. El concepto tiene un papel central en la lógica interpretativa de Nietzsche, la cual atribuye a Heráclito una concepción amoral del mundo como juego estético. La justicia eterna expresa, en efecto, el carácter aparente de las diferencias entre culpa y mérito, castigo y premio y, en el límite, la insustancialidad de la distinción misma entre bien y mal. Sin contar además con que el carácter esencial de la eterna justicia es usado, en el parágrafo 51 de El mundo, como definición de la tragedia: «Lo que emerge aquí [en la tragedia] a la luz es la lucha espantosa de la voluntad consigo misma; lucha que, en este grado supremo de objetivación, se despliega en el ámbito más vasto y completo [...] Una y la misma es la voluntad que vive y se revela en todos los seres humanos, pero sus manifestaciones se atacan y se combaten mutuamente».

En la época de El nacimiento de la tragedia, apoyándose además en las lecciones de Burckhardt sobre la historia de la cultura griega, Nietzsche pone a punto, con los conceptos de agón y de agonismo, un modelo pluralista y conflictivo de civilización, en contradicción profunda con el modelo (dominante en esta fase) de una comunidad orgánica basada sobre el mito y las 'ilusiones' generadas por el genio artístico. En los años que van desde La gaya ciencia a La genealogía de la moral, y más allá, el debate de Nietzsche con Schopenhauer no se debilita, más bien se hace en lo posible más estrecho y puntual, al estar dirigido ahora por el intento de conquistar una propia autonomía. Las frecuentes referencias, y a menudo la trascripción o la paráfrasis de pasajes schopenhauerianos, demuestran la necesidad, por parte de Nietzsche, de no abandonar una confrontación directa, y Schopenhauer permanece siendo un interlocutor de primerísimo orden en las atormentadas reflexiones de Nietzsche sobre el concepto de voluntad de poder. La misma valoración de

${ }^{12} \mathrm{KGW}$ II/4 295.

${ }^{13} \mathrm{KGW}$ II/4 272.

Estudios Nietzsche, 3 (2003), ISSN: 1578-6676, pp. 11-26 
Schopenhauer parece hacerse más problemática, acentuando el carácter contradictorio y casi dramático del filósofo. En el fragmento 34[111] de abriljunio 1885, Nietzsche llega a hablar, a propósito de la oscilación de Schopenhauer entre instancias 'volterianas' y románticas, de una «íntima discordia», haciendo de la característica que el filósofo asignaba a la voluntad el rasgo dominante de su personalidad. Pero La gaya ciencia, que desarrolla ampliamente esta valoración, subraya además (aforismo 357) que la contradicción más profunda de Schopenhauer es la existente entre la 'honestidad' de su ateísmo ( Schopenhauer fue el primer ateo declarado e inamovible que hayamos tenido nosotros los alemanes»), que lo lleva a una decidida desdivinización de la existencia -el aforismo habla de su «mirada aterrorizada en un mundo desdivinizado», y de su «honesto terror»-, y por otra parte su reexhumación de una perspectiva teológica de ascetismo y negación de la vida, propia de la tradición cristiana. La insistencia en este tema está atestiguada por dos fragmentos de 1887 (9[42] y 10[150]), donde igualmente Schopenhauer es acusado de haber traicionado sus propias promesas, recayendo, a causa de su servidumbre a la moral cristiana, en el teísmo que había combatido cuando desdivinizó el mundo. Curiosamente, Nietzsche combate a Schopenhauer con sus mismas armas, y le echa en cara la misma contradicción que Schopenhauer había resaltado en Kant, cuando con el imperativo categórico había reintroducido por la ventanita al 'teísmo' que la Crítica de la razón pura había echado victoriosamente por la puerta. También Schopenhauer es como «un zorro que, perdido, vuelve a su jaula», como Nietzsche escribe en La gaya ciencia a propósito del imperativo de Kant, aceptando plenamente el sentido de la crítica schopenhaueriana en El fundamento de la moral.

El «dominio absoluto de los valores morales» en la filosofía schopenhaueriana se refleja también en su concepción del genio: el fragmento 10[118] del otoño 1887 opone a la concepción schopenhaueriana del genio, como figura del desprendimiento de la voluntad en la contemplación, la inmoralidad del genio, en el ámbito de una interpretación del arte como potenciación 'inmoral' de la voluntad. Además, es éste un punto esencial de la polémica de Nietzsche contra el cristianismo y el 'budismo' de Schopenhauer, que culmina en la reivindicación del «derecho al gran afecto» ${ }^{14}$ : «El error llegó a su culminación cuando Schopenhauer enseñó que precisamente en el liberarse del afecto, de la voluntad, reside el único acceso a la 'verdad', al conocimiento; el entendimiento desvinculado de la voluntad no podría hacer otra cosa más que ver la esencia auténtica de las cosas. / El mismo error en arte: como si todo fuese bello, apenas es contemplado sin voluntad. / La lucha contra la 'finalidad' en el arte es siempre la lucha contra la tendencia moralizante en arte: l'art pour l'art significa “ ¡Al diablo la moral!"». Schopenhauer es la última campanada

${ }^{14}$ KSA XII 404, 9[119]. 
del siglo XVIII y el síntoma de una extenuación que se manifiesta justamente en la idea de un sujeto desprendido de la voluntad; es en definitiva el continuador de la idea pascaliana que sin cristianismo el hombre no es más que «un monstre et un chaos» ${ }^{15}$, para concluir después que «en su lucha contra el siglo XVIII, Schopenhauer recae sin embargo involuntariamente en el XVIII y se revela como un moderno Pascal [...] no era lo bastante fuerte para un nuevo sí».

III

En las reflexiones de Nietzsche sobre la transvaloración y sobre la voluntad de poder, Schopenhauer no es traído a colación únicamente como objetivo polémico, por la negación ascética de la voluntad o por el presupuesto de un sujeto desprendido del querer; más bien, la misma definición de voluntad de poder no puede prescindir de una confrontación y una descomposición del concepto schopenhaueriano de voluntad, y Nietzsche parece utilizar algunos corolarios del 'disidio' de la voluntad para construir el concepto de voluntad de poder. Ante todo, la crítica a la metafísica schopenhaueriana de la voluntad -que culmina en la exclamación «iNo existe una voluntad!» del otoño $1887^{16}$ constituye el presupuesto necesario del concepto de voluntad de poder. En los apuntes de 1876-77, Nietzsche comienza decididamente a desgranar las simplificaciones conceptuales y lingüísticas conectadas a los términos que indican sentimientos, instintos, afectos, y presentan como espontaneidad e inmediatez lo que deriva en cambio de complejos procesos llenos de motivaciones intelectuales y hábitos mentales incorporados. También el concepto schopenhaueriano de voluntad de vivir, anota Nietzsche, no ha adquirido derecho de ciudadanía a los ojos de la ciencia, ni siquiera si se reduce, como hace Mainländer, a una multiplicidad de voluntades individuales, exactamente como no tienen ciudadanía las nociones de alma, dios y fuerza vital ${ }^{17}$. La búsqueda del placer y la huida del dolor, una situación que Schopenhauer pretende presentar como un «dato de hecho primero y originario», presupone en realidad una experiencia acumulada y por tanto el entendimiento. A esta consideración concerniente el horizonte, ya delineado en Humano, demasiado humano, de intelectualización e historización de una presunta naturaleza del mundo instintivo, Nietzsche añade enseguida la observación que cuando se habla de naturaleza «incluso los pensadores más libres» recurren a instan-

${ }^{15}$ KSA XII 182, 9[182].

${ }^{16}$ KSA XII 391, 9[98].

${ }^{17}$ KSA VIII 406 ss., 23[12] (finales 1876 - verano 1877).

Estudios Nietzsche, 3 (2003), ISSN: 1578-6676, pp. 11-26 
cias mitológicas, de modo que «Voluntad y naturaleza son la supervivencia de la antigua fe en los dioses» ${ }^{18}$. La crítica al concepto schopenhaueriano de voluntad, en cuanto que es la supervivencia de un arcaísmo religioso condicionado por la naturaleza mitopoiética del lenguaje, que crea sujetos-substancias allí donde sólo hay conjuntos de relaciones (la crítica culmina en la segunda mitad de los años ochenta con la desconstrucción del concepto de sujeto) tiene su origen lejano, pero claramente reconocible, en los apuntes de Leipzig de 1868 sobre Schopenhauer, donde se puede leer que la voluntad como cosa en sí es «una palabra de acuñación grosera y muy comprensiva» y «sólo formada gracias a una intuición poética» ${ }^{19}$. A pesar de las sucesivas complicaciones y variaciones del tema, Nietzsche no desmentirá nunca, en el fondo, esta interpretación, y en el largo fragmento 38[8] de junio-julio 1885, titulado «La voluntad», ella es tratada como «esta cosa tan complicada, para la cual el pueblo tiene una única palabra», o como un «torpe prejuicio» ${ }^{20}$, derivado de la convicción supersticiosa de tener entre manos, en lugar del resultado de un conjunto complejo de procesos, una «inmediata certeza» o un «dato de hecho básico» ${ }^{21}$.

Si se compara este último fragmento con los sucesivos 40[42] y 40[55] y con el aforismo 19 de Más allá del bien y del mal, se puede constatar que la crítica a la metafísica de la voluntad precede inmediatamente a la presentación de un carácter fundamental de la voluntad de poder. La voluntad como prejuicio popular es sustituida en el aforismo por un 'afecto', o un «afecto del mando [Affekt des Commandos]», que es esencialmente" «el afecto de superioridad respecto a quien debe obedecer» ${ }^{22}$ y a lo que se reduce en definitiva la pretendida libertad del querer. Nietzsche la evoca varias veces, citando de manera explícita o implícita los escritos schopenhauerianos sobre la ética, y aquí la identifica con el sentimiento o estado de placer del que quiere, mientras más adelante, en la quinta parte de la obra («Historia natural de la moral»), el Sollen se le presenta como el resultado de una costumbre acumulada de obediencia. Por consiguiente, los conceptos morales son abordados bajo la óptica de la voluntad de poder, en cuanto dialéctica de la obediencia y del dominio en un campo dinámico donde las fuerzas entran en confrontación según equilibrios cambiantes. En los dos fragmentos recordados de agostoseptiembre 1885, la argumentación pasa al terreno biológico y Nietzsche hipotiza una «aristocracia de las células» que detenta el dominio. La única fuerza, de tipo parecido a la voluntad, que actúa es «una especie de mandar sobre

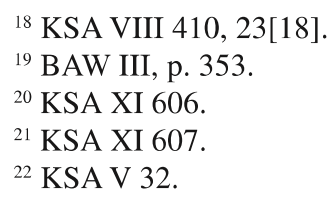


otros sujetos, que con ello cambian». La noción misma de ley natural debe ser abolida para dejar sitio a la «brutalidad» de las «relaciones de poder». La lucha, característica común a lo viviente, debe ser entendida de manera 'profunda', en el sentido de que sigue subsistiendo incluso cuando la relación entre dominante y dominado se ha asentado, de modo que es necesario «entender también la relación entre dominante y dominado como un luchar, y la relación de quien obedece con el dominante como un activo contraponerse [ein Widerstreben]» ${ }^{23}$.

No obstante, podemos decir que la concepción dinámica de las relaciones de fuerza, la concepción más 'profunda' de la lucha, está presente en Nietzsche al menos desde el otoño de 1884. La lucha no se agota en la nutrición o en la posesión de los medios de supervivencia, sino que sigue existiendo más allá, al estar impulsada por una «voluntad de lucha por la lucha». La definición del dominio es de naturaleza dialéctica en los dos polos del enfrentamiento, ya que dominar significa «soportar el contrapeso del más débil» y obedecer significa a su vez luchar, como ejercicio de una fuerza de resisten$\mathrm{cia}^{24}$. A continuación, Nietzsche extiende este modelo de lucha y hegemonía con equilibrios dinámicos de las fuerzas, a la problemática del devenir y de la finalidad. En su compleja estructura argumentativa, el fragmento $9[91]^{25}$ introduce este tema en un marco crítico radical hacia los conceptos de necesidad del acontecer («la necesidad no es un hecho, sino una interpretación»), de sujeto y objeto (tratados como «ficciones»), de substancia y de verdad. Esta última es «voluntad de verdad», esfuerzo de fijar y volver perdurable lo que está sometido al devenir: no se trata por tanto de hallar o descubrir algo que en sí es «sólido y determinado», sino de un acto de construcción activa. En este campo, dominado por la movilidad de las relaciones y por la pluralidad de las interpretaciones perspectivistas, también la noción de finalidad es relativizada como consecuencia de la voluntad de poder que obra en todo ámbito. Lo que se muestra como finalidad no es más que «la expresión para indicar la ordenación de esferas de poder y su juego mutuo»: en cuanto una potencia o fuerza adquiere superioridad sobre otra y esta última 'trabaja' en calidad de función de la fuerza dominante, se produce una «ordenación según el rango [Rangordnung]», que asume el aspecto de una relación medio-fin.

La voluntad de poder, como afecto del mando, presenta entonces dos aspectos o condiciones complementarias. Ante todo el de la lucha, gracias al cual en la relación mandar/obedecer las fuerzas mantienen su identidad dinámica, sin apagarla o negarla en un equilibrio estático: la fuerza dominante continua sobrepujando, la dominada resistiendo. Pero en segundo lugar -tal como dice el fragmento 9[91]- la lucha no se resuelve en una sucesión de

\footnotetext{
${ }^{23}$ KSA XI 655.

${ }^{24}$ KSA XI 222, 26[276]. Cf. también KSA XI 281, 27[24]. 
oposiciones en las que las energías de los contendientes se consumen, desgastándose mutuamente, sino que da lugar a una ordenación basada en el rango, hasta el punto de que un contendiente se presenta como medio del otro, que se impone y realiza como fin. En el prefacio de 1887 a Humano, demasiado humano, Nietzsche asigna al ordenamiento de rango una importancia tal como para convertirlo en la idea dominante y central de la existencia; en el texto de Ecce homo citado al inicio se habla de «ordenamiento de rango de las facultades», comparándolo con la «distancia», con el arte de dividir sin crear contrastes, con el rechazo de mezclar y conciliar, a fin de crear la «gran multiplicidad» no caótica, sino ordenada bajo una forma. Mientras que el acercamiento de Rangordnung y pathos de la distancia retoma el presentado, con un duro tono señorial, en el aforismo 257 de Más allá del bien y del mal, en este pasaje emerge la otra característica del Rangordnung, es decir, la función de garantizar la pluralidad evitando tanto las conciliaciones como la disipación de la energía, debida al choque entre las fuerzas dispuestas ilegítimamente en el mismo plano, e inducidas por tanto a neutralizarse mutuamente. El arte de 'separar' es para Nietzsche un arte de la jerarquía funcional para la conservación de la energía conjunta, y el mismo concepto del pasaje de Ecce homo es expresado, de manera más explícita, en un fragmento del otoño de $1887^{26}$ donde «oposiciones» (Gegensätze) y Rangordnung son presentadas como perspectivas antitéticas. Es evidente que el modelo social, en lugar de mecánico, mediante el cual piensa la transferencia de las fuerzas, hace que Nietzsche interprete todos los procesos de transformación de lo viviente y de acumulación de las energías en los términos de una filosofía del dominio.

En las lecciones sobre Nietzsche de 1936-1937, Heidegger -influenciado ciertamente por Baeumler ${ }^{27}$ - había reconocido en el «afecto del mando» la función esencial de la voluntad de poder. Según Heidegger, acentuando «de distintas maneras» el carácter de mando de la voluntad, Nietzsche pretende resaltar la «resolución [...] con la cual el querer posee un impulso que apunta al volente y a lo querido, y este impulso en los términos de una firmeza fundada, estable»; en el «lanzarse más allá de sí» la voluntad se califica como voluntad de poder. No sin buenos motivos, Heidegger lee en la voluntad como afecto del mando una inversión de la posición de Schopenhauer, para el cual existe al contrario un 'puro querer' que prescinde, tanto de la determinación

${ }^{25}$ Otoño 1887 , KSA XII 383-387.

${ }^{26}$ KSA XII 397, 9[107].

${ }^{27}$ En efecto, en Baeumler encontramos ya la afirmación de que el «afecto del mando» es el núcleo de la voluntad de poder: "Querer es mandar, pero el mandar es un afecto, y este afecto es una "improvisa explosión de fuerza"» Nietzsche der Philosoph und Politiker, Reclam, Lepizig, 1931, p. 47. Baeumler extrae de ello la consecuencia de que en Nietzsche el querer equivale al 'poder' (Können): es un «poner a prueba la fuerza», que no se interroga en absoluto sobre los fines, un actuar fin a sí mismo.

Estudios Nietzsche, 3 (2003), ISSN: 1578-6676, pp. 11-26 
de lo querido (que para Schopenhauer es sólo la causa ocasional del manifestarse de la voluntad), como de la presencia del volente ${ }^{28}$. A causa quizás de su desvalorización de la posición histórica del pensamiento de Schopenhauer, juzgado como un punto de decadencia respecto a las alturas especulativas alcanzadas por el idealismo post-kantiano, Heidegger se cierra a sí la captación de una relación de tipo no exclusivamente polémico entre la voluntad de Schopenhauer y la nietzscheana voluntad de poder, un rasgo afín que puede establecerse precisamente a través de la asimilación de la voluntad al afecto del mando.

En el parágrafo 27 de El mundo como voluntad y representación, la fenomenología del conflicto entre las fuerzas-ideas es interpretada como una forma de asimilación hegemónica, en la que la individualidad de las fuerzas en juego es mantenida y da lugar, por así decirlo, a un recíproco reconocimiento: como Nietzsche, Schopenhauer habla de una subyugación [Überwältigung]asimilación, y de una 'resistencia' de las fuerzas dominadas. El organismo, cuya definición es el objetivo de la argumentación de Schopenhauer, no es el resultado de una combinación de fuerzas físicas y químicas, «sino que es una idea superior que ha subyugado todas las otras ideas inferiores mediante una asimilación subyugante [überwältigende Assimilation] [...] Ninguna victoria sin batalla: la idea o la objetivación más alta de la voluntad, que por un lado no puede surgir más que venciendo a las inferiores, tiene que mantener la resistencia de estas últimas; las cuales, aunque reducidas a servidumbre, aspiran siempre a manifestar su propia esencia de modo completo e independiente. Como el imán que ha levantado un hierro mantiene una asidua lucha con la gravedad (la cual, en cuanto objetivación más baja de la voluntad, tiene un derecho originario sobre la materia del hierro) -lucha en la que el imán se fortifica, porque la resistencia del hierro lo excita a multiplicar los esfuerzos-, del mismo modo todo fenómeno tiene que sostener una lucha perpetua contra las numerosas fuerzas físicas y químicas que, en calidad de ideas inferiores, reivindican un derecho más antiguo sobre la misma materia» ${ }^{29}$.

Añadamos que esta perspectiva había sido formulada claramente por Schopenhauer ya desde 1816, año en el que da una definición del conflicto y de la hegemonía de las fuerzas superiores que le permite pensar juntas la unidad (el plano de la naturaleza) y la pluralidad no reducible, si no es constituyendo una sólida jerarquía, de las fuerzas, una preocupación que continuará a ocupar una lugar central también en el texto de El mundo. Justamente con este objetivo introduce el concepto schellinguiano de 'potencia' (Potenz): cuando una pluralidad de fuerzas entra en un estado de conflicto, se unifican para formar una entidad que «es a las primeras como el cuadrado o el cubo al radical»; para

${ }^{28}$ M. Heidegger, Nietzsche, Pfüllingen, Neske, 1961, vol. I, pp. 51 ss.

${ }^{29}$ A. Schopenhauer, op. cit., $\$ 27$. 
hacer posible este acrecentamiento (Steigerung), una fuerza debe someter a las otras, y vencer su resistencia mediante un compromiso mimético. Ella «asume algo del ser de las subyugadas, de modo que se descubre en ellas algo análogo a este ser, y sin embargo algo completamente distinto: así por ejemplo el soldarse de los huesos, de la carne, es un análogo de la cristalización, que antes dominaba en esta materia; la mezcla de jugos en el cuerpo animal es un análogo de la mezcla química y sin embargo muy distinta de ella y no producible por el cuerpo animal» ${ }^{30}$.

Gracias a la Steigerung, el éxito del conflicto entre fuerzas, que aquí no son más que sistemas de organización de la materia, sobrepasa las condiciones iniciales. La estructura polar o antagonista en la que se consumen las energías, y que sigue siendo el presupuesto del modelo construido por Schopenhauer, va en función de una dinámica ascendente. En un estudio reciente, Konstantin Broese, desarrollando una observación de Salaquarda, ha hecho notar que gracias a la categoría de Steigerung Schopenhauer otorga a las manifestaciones de la voluntad una aspiración al crecimiento, y ofrece implícitamente a Nietzsche un instrumento para criticar la primacía del principio de autoconservación en la vida orgánica ${ }^{31}$. No obstante, hay que hacer notar que es justo en la noción de Steigerung donde se manifiesta aquella tendencia a leer los fenómenos naturales bajo una óptica moral, que Nietzsche reprocha constantemente a Schopenhauer. Mediante la Steigerung, la filosofía de la naturaleza es sometida a las exigencias de la filosofía de la redención que está a la base de la obra: la escala de las formas y de los fenómenos es graduada sobre la base de una mayor o menor 'perfección', y las ideas menos perfectas se someten a las más perfectas porque es en estas últimas donde puede tener lugar el 'giro' (Wendung) que conduce a la negación de la voluntad y redime a toda la materia. Por consiguiente, es mediante la idea de Steigerung como el 'plan de la naturaleza' de Schopenhauer adquiere la impronta teleológica que Nietzsche rechaza.

Complementaria a ella es, no obstante, la dimensión de la pluralidad: ninguna de las fuerzas que entran en conflicto y son sometidas, se echa a perder, ni siquiera la más ínfima. Ella sigue haciendo valer sus derechos incluso donde ya se ha afirmado la instancia más alta. En un pasaje que Schopenhauer ha insertado en su copia de trabajo de El mundo, y que podemos leer en el aparato crítico de la edición crítica realizada por Otto Weiß, la imagen elegida para subrayar la indestructibilidad de las fuerzas inferiores es la de la fuerza de gravedad que amenaza en cada instante la danza del funámbulo, de tal manera

${ }^{30}$ A. Schopenhauer, Handschriftliche Nachlaß, ed. A. Hübscher, DTV, München, 1985, vol. I, p. 385.

${ }^{31} \mathrm{~K}$. Broese, Schopenhauers Metaphysik des Willens als Metaphysik zwischen kants Kritizismus und Nietzsches Radikalkritizismus, (Dissertation) Mainz, 2003, p. 246 ss.

Estudios Nietzsche, 3 (2003), ISSN: 1578-6676, pp. 11-26 
que está obligado a afrontar sin paradas un desafío extremo: «Lo que hace significativa esta impresión es el contraste entre la materia que se ha incrementado a través de todos los grados físicos, químicos, vegetativos y animales, hasta esta forma humana que se mueve, irguiéndose y plegándose según las intenciones más sutiles, y la gravedad, que en cuanto idea más baja de todas opera sobre la materia un derecho originario, y que incluso aquí, en presencia de una idea que le queda lejanísima, no renuncia a él, sino que también reivindica su derecho sobre esta forma, como si quisiese recordarle que también ella sigue siendo materia, aunque haya conocido un incremento hasta un nivel tan alto» ${ }^{32}$.

También el texto de El mundo, que afirma con igual claridad la línea ascendente del conflicto, deja abierta la alternativa opuesta, que continua afectando amenazadoramente a todo el sistema. La resistencia de las fuerzas inferiores puede funcionar como 'estímulo' para el incremento de las superiores, como hemos visto, pero puede también arrastrar a su nivel el edificio erigido sobre complicadas relaciones dinámicas. El parágrafo 27 indica con claridad una perspectiva de degradación energética, en la que la resistencia de las fuerzas inferiores arrastra consigo una vida orgánica extenuada hacia la inmovilidad de la muerte, una perspectiva que quizá le fuese sugerida a Schopenhauer por Lamarck, y que más tarde habría sido confirmada por las Reflexions sur la vie et sur la mort del admiradísimo Bichat. Entonces «las fuerzas naturales subyugadas [...] arrancan al organismo, extenuado por sus propias continuas victorias, la materia que les había sustraído, y llegan a manifestar sin obstáculo la propia naturaleza».

Toda la argumentación del parágrafo 27 de El mundo está inserta en el contexto más amplio de una discusión sobre el concepto kantiano de finalidad en la vida orgánica. La existencia de una finalidad es para Schopenhauer indiscutible y el «estupor teleológico» sólo es producido por el hecho de que, mediante el entendimiento, nosotros reconocemos como armonía de las partes o de los momentos separados en el espacio y en el tiempo lo que en la voluntad, considerada en su unidad metafísica, es indistinguible. En el capítulo «Sobre la teleología» del segundo volumen de $E l$ mundo, el esfuerzo de Schopenhauer va dirigido a distinguir entre teleología y teología (a esta fatal confusión le echa el cargo de la aversión de Spinoza hacia las causas finales) y a decretar la superioridad explicativa de las causas finales respecto a las eficientes. El texto de Schopenhauer no se libera nunca de este presupuesto; el conflicto y el pluralismo de las fuerzas es un juego gobernado tras los bastidores por una única voluntad, que no concede libertad alguna a sus expresiones fenoménicas, si bien la finalidad a la que son sometidas es naturalmente ciega e inconsciente.

${ }^{32}$ A. Schopenhauer, Die Welt als Wille und Vorstellung, ed. O. Weiß, Hesse \& Becker, Leipzig, 1919, vol. I, p. 785.

Estudios Nietzsche, 3 (2003), ISSN: 1578-6676, pp. 11-26 
Nietzsche se había medido con estos problemas en los apuntes «Sobre la teleología» de abril de 1868, y había invertido la tesis de Schopenhauer: la vida representa «algo completamente oscuro, que no podemos aclarar ni siquiera recorriendo a causas finales ${ }^{33}$. Aludiendo sin duda a la separación entre teología y teleología operada por Schopenhauer, Nietzsche observa escépticamente que «el punto de vista de la filosofía de la naturaleza» evita recurrir a una inteligencia creadora, y está obligada sin embargo a recurrir a una cosa en sí. Pero para nosotros el pasaje más interesante de estos apuntes es aquél en que Nietzsche contrapone el schopenhuaeriano consensus naturae, que manifiesta la presencia de una teleología, al modelo conflictivo: «Todas las partes de la naturaleza se oponen unas a otras, ya que una sola es la voluntad. Pero lo que se opone a la entera teoría es aquella terrible lucha de los individuos y de las especies. La explicación presupone por tanto una teleología sin lagunas: la cual no existe» ${ }^{34}$.

La crítica a Schopenhauer es tajante, pero Nietzsche parece utilizar y casi citar un pasaje del primer volumen de El mundo (\$27), donde la «adaptación recíproca de los fenómenos resultante de su unidad» (es decir, de su referirse común a la voluntad única) parece funcionar, no tanto como principio exclusivo, sino más bien como corrección de un conflicto que arriesga conducir individuos y formas a su mutua destrucción. Toda la discusión de Nietzsche con Schopenhauer, sobre el tema de la voluntad de poder, parece seguir los trazos esbozados por esta idea juvenil, y busca separar teleología (con su referencia metafísica a la voluntad única) del modelo del devenir conflictivo.

El resultado de este esfuerzo de separación es registrado en un texto que ha tenido grandes efectos sobre el pensamiento contemporáneo, y que recientemente ha sido interpretado como una polémica hacia la teleología positivista -de Spencer en especial- y como animado por una densa discusión con textos científicos de la época ${ }^{35}$. Si la hipótesis adicional que propongo no está equivocada, nos hallamos ante uno de tantos ejemplos del carácter siempre estratificado y complejo de las 'fuentes' de Nietzsche: éstas no deben ser nunca valoradas de manera aislada y exclusiva, porque el proceso de la invención conceptual y literaria las aglomera en un conjunto que luego es difícil de desgranar trazando tajantes límites entre los componentes que contiene. El texto en cuestión es el parágrafo 12 de la segunda disertación de La genealogía de la moral; su punto de partida es una discusión sobre la finalidad de la pena, y Nietzsche niega que tal finalidad (por ejemplo, la intimidación o la venganza) pueda ponerse en el origen de la historia de la pena y asumida como su causa

\footnotetext{
${ }^{33}$ BAW III p. 388.

${ }^{34}$ BAW III, p. 373

${ }^{35}$ A. Orsucci, Genealogia della morale. Introduzione alla lettura, Carocci, Roma, 2001, pp. 67-80.
}

Estudios Nietzsche, 3 (2003), ISSN: 1578-6676, pp. 11-26 
explicativa. Del mismo modo, la utilidad o la finalidad de un órgano fisiológico no dice nada sobre su origen. El proceso orientado según un fin es sustituido por otra perspectiva, en la que «todo acontecimiento del mundo orgánico es un subyugar [Überwältigen], un señorear [Herrwerden], y a su vez todo subyugar y señorear es un reinterpretar de nuevo [Neu-Interpretieren], un reorganizar, en el que necesariamente el 'sentido' y el 'fin' habidos hasta ese momento deben oscurecerse o extinguirse del todo [...] Pero todos los fines, todas las utilidades son únicamente indicios del hecho de que una voluntad de poder le ha imprimido, sobre la base del propio arbitrio, el sentido de una función; y la entera historia de una 'cosa', de un órgano, de un uso puede ser de tal manera una ininterrumpida cadena de signos, que expresa siempre nuevas interpretaciones y reorganizaciones... ${ }^{36}$ En este pasaje, donde es evidente la equivalencia entre interpretación y voluntad de poder, y donde la perspectiva de liberación, abierta por la crítica de las hipóstasis metafísicas, se presenta como el corolario de una dialéctica del dominio, también sigue estando completamente abierto el problema de si Nietzsche, acogiendo un modelo de relaciones sociales para describir la transmisión de las fuerzas, no depende también, en la interpretación de la naturaleza, de aquel esquema antropomórfico que había reprochado a Schopenhauer.

traducción de Marco Parmeggiani 